Research report

\title{
Naming facilitation induced by transcranial direct current stimulation
}

\author{
Anna Fertonani ${ }^{\mathrm{a}, \mathrm{b}}$, Sandra Rosini ${ }^{\mathrm{a}}$, Maria Cotelli ${ }^{\mathrm{a}}$, Paolo Maria Rossini ${ }^{\mathrm{b}}$, Carlo Miniussi ${ }^{\mathrm{a}, \mathrm{c}, *}$ \\ a Cognitive Neuroscience Section, IRCCS San Giovanni di Dio Fatebenefratelli, Brescia, Italy \\ ${ }^{\mathrm{b}}$ Department of Neurology, University Campus Biomedico of Roma E AFaR Isola Tiberina Fatebenefratelli, Roma, Italy \\ ${ }^{c}$ Department of Biomedical Sciences and Biotechnologies E'National Institute of Neuroscience, University of Brescia, Brescia, Italy
}

\section{A R T I C L E I N F O}

\section{Article history:}

Received 7 September 2009

Received in revised form 19 October 2009

Accepted 23 October 2009

Available online 31 October 2009

\section{Keywords:}

Transcranial direct current stimulation

Naming

Language

Cognition

Prefrontal cortex

\begin{abstract}
A B S T R A C T
Transcranial direct current stimulation (tDCS) is able to generate a long-term increase or decrease in the neuronal excitability that can modulate cognitive tasks, similar to repetitive transcranial magnetic stimulation. The aim of this study was to explore the effects of tDCS on a language task in young healthy subjects. Anodal, cathodal and sham tDCS were applied to the left dorsolateral prefrontal cortex (DLPFC) before two picture naming experiments, a preliminary study (i.e., experiment 1) and a main study (i.e., experiment 2). The results show that anodal tDCS of the left DLPFC improves naming performance, speeding up verbal reaction times after the end of the stimulation, whereas cathodal stimulation had no effect. We hypothesize that the cerebral network dedicated to lexical retrieval processing is facilitated by anodal tDCS to the left DLPFC. Although the mechanisms responsible for facilitation are not yet clear, the results presented herein implicate a facilitation lasting beyond the end of the stimulation that imply cortical plasticity mechanisms. The opportunity to non-invasively interact with the functioning of these plasticity mechanisms will surely open new and promising scenarios in language studies in basic and clinical neuroscience fields.
\end{abstract}

(C) 2010 Published by Elsevier B.V.

\section{Introduction}

A large number of neuroimaging studies highlight that the ability to name actions or objects is achieved by a wide and complex cerebral network. This system involves, among other areas, the left prefrontal and temporal areas [22,35], as demonstrated by neuroimaging $[35,41]$ and brain lesion $[10,23]$ studies. The crucial role of the left dorsolateral prefrontal cortex (DLPFC) in action naming has also been confirmed by repetitive transcranial magnetic stimulation (rTMS) studies [6-8]. Cappa et al. [6] reported that high frequency rTMS of left DLPFC significantly reduced the vocal reaction times for naming of action pictures. This interesting result has been subsequently confirmed in Alzheimer disease patients [7], extending the effect to object naming [8] and to a patient affected by primary progressive aphasia [11].

Recently, a lot of interest has been captured by the rediscovery of a cerebral stimulation technique that acts through the application of a very low direct current [27,37]. Transcranial direct current stimulation (tDCS) seems to act by modulating the resting membrane potential, in an opposite direction depending on the

\footnotetext{
* Corresponding author at: Department of Biomedical Sciences and Biotechnologies, University of Brescia, Viale Europa 11, 25123 Brescia, Italy. Tel.: +39 0303501597; fax: +390303533513.

E-mail addresses: miniussi@med.unibs.it,cminiussi@fatebenefratelli.it (C. Miniussi).
}

polarity (anodal vs. cathodal) of the electrode placed on the chosen area. A very interesting characteristic is the duration of these neuromodulatory effects. The first studies on the human motor cortex [29,31] have shown that 13 min of anodal stimulation induce 90 min of increased cortical excitability (enhanced resting motor evoked potentials - MEPs amplitude) or that, in a similar way, but with opposite results, cathodal stimulation causes $60 \mathrm{~min}$ of diminished cortical excitability (reduced resting MEPs amplitude).

The mechanisms underlying these effects have been first studied in animals, in the 1960s $[4,9,15,16,39]$. In humans, Liebetanz et al. [21] demonstrated that short-term tDCS effects are related to membrane depolarisation (anodal stimulation) or hyperpolarisation (cathodal stimulation), while long-term tDCS effects involve the participation of glutamatergic NMDA receptors. We now know that synaptic plasticity, i.e., modulation of the strength of synaptic connections on the basis of experience, is dependent on NMDA receptors, as we know that plasticity is the basis for learning and memory [26]. If we consider that a brain injury, such as stroke or a neurodegenerative disease, can damage this system, the opportunity to non-invasively modulate the functioning of these mechanisms can open new prospects for the neurorehabilitation of brain-damaged patients [see 24,40].

In the past years, several studies have sought to durably modify cortical excitability. Behavioural facilitatory effects have been highlighted with regard to implicit motor learning [33], associative learning [12], working memory [13,34], pitch memory [44], perception [2] and language $[17,25,43]$. This facilitatory function may be 
very important, not only in establishing the role of the stimulated area, but also because it can be used to enhance reduced function in cognitive neurorehabilitation.

Our work aims to explore the effects of tDCS on picture naming, making use of a task that was previously studied with rTMS in normal [6] and Alzheimer's patients [7,8]. We hypothesize that anodal stimulation of the DLPFC can generate a facilitatory effect, namely a decrease of the vocal reaction times in action and/or object naming.

\section{Methods}

Two picture naming experiments were conducted with normal young subjects after the end of a tDCS period over the DLPFC.

\section{Subjects}

Twelve healthy subjects ( 4 males, mean age 24.1 years, standard deviation 3.7, range 19-32) took part in the experiment 1 and 12 other healthy subjects participated in the experiment 2 (6 males, mean age 21.8 years, standard deviation 1.0, range 20-23). Each subject participated in only one of the two experiments.

Subjects were native Italian speakers, right-handed and with normal or corrected-to-normal vision. We did not include subjects with a history of seizures, implanted metal objects, heart problems or any other neurological disease. The study was approved by the Ethics Committee of IRCCS San Giovanni di Dio Fatebenefratelli, Brescia, Italy. Informed consent was obtained from participants prior to the beginning of the experiment.

\section{Experimental tasks}

\subsection{Picture naming task}

Stimuli for the picture naming task were presented on a personal computer screen using the software Presentation v. 12.0 (http://www.neurobs.com). All of the stimuli were black and white two-dimensional line drawings taken from the corpus of the CRLIPNP (Center for Research in Language - International Picture Naming Project; http://crl.ucsd.edu/ aszekely/ipnp), a broad set of 795 action and object pictures. These items have been tested in healthy and patient populations across seven different international sites and languages. Items are coded for a number of variables known to influence naming difficulty, including initial word frequency, age of acquisition and picture image ability scores. These variables have been tested to assess their influence on the participants' naming performance [3].

The picture naming task used in the two experiments was made up of three experimental blocks and a practice block. In the experiment 1, each experimental block included 15 object and 15 action images. While in the experiment 2 each block included 14 object and 14 action images accurately selected from a larger dataset, tested in a behavioural experiment not reported here. The selection of a subset of stimuli from a larger set was done to obtain a congruent subset of stimuli balanced for all variables and verbal reaction time responses. In both experiments, the practice block included nine object and nine action images.

The subjects were required to accurately name, as fast as possible, the stimuli appearing on the computer screen. The trial structure for experiment 1 is illustrated in Fig. 1a. In experiment 2 , we added the indication "action" or "object" immediately before the picture presentation in order to disambiguate lexical selection. This second trial structure is illustrated in Fig. 1b.

\subsection{Attentive task}

To exclude the possibility that the tDCS effect could be ascribed to a general enhancement of arousal by anodal stimulation, we (a)
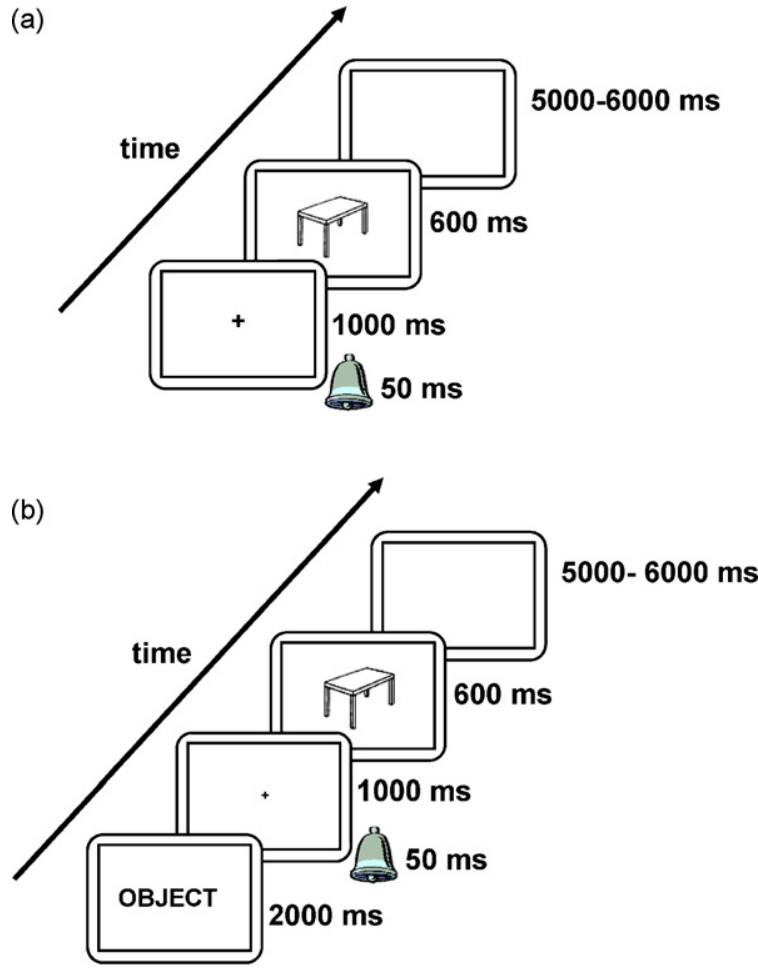

(c)

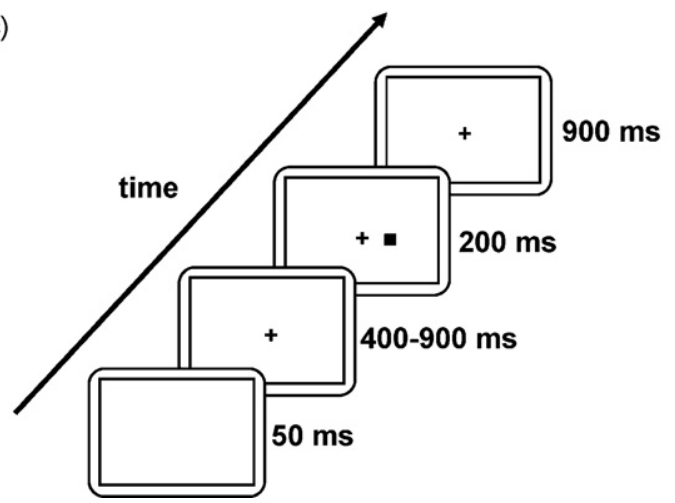

Fig. 1. Trial structure of the picture naming task in the two experiments: (a) experiment 1 and (b) experiment 2. (c) Trial structure in the attentive control task.

introduced an attentive control task using the same computer and software as used for the picture naming task. The attentive task comprised two equal blocks. There were 44 trials in each block. The structure of each trial is depicted in Fig. 1c. After $50 \mathrm{~ms}$ of white screen, a fixation cross appeared at the centre of the screen for a time varying from 400 to $900 \mathrm{~ms}$. A small black square was presented for $200 \mathrm{~ms}$ at the right or left of the fixation cross. After the disappearance of the square, the fixation cross remained on the screen for another $900 \mathrm{~ms}$. In every block, there were 20 trials in which the square was presented to the right of the fixation cross and 20 with the square to the left; the remaining four trials were catch trials (no square appearance). We asked the subjects to respond as fast as possible, by pressing the space bar at the appearance of the stimulus. They used the left hand in one block and the right hand in the other, in an inter-subject counterbalanced manner.

\section{Transcranial direct current stimulation}

The stimulation was delivered by a battery-driven, constant current stimulator (neuroConn $\mathrm{GmbH}$, Ilmenau, Germany) through 
(a)

Experiment 1
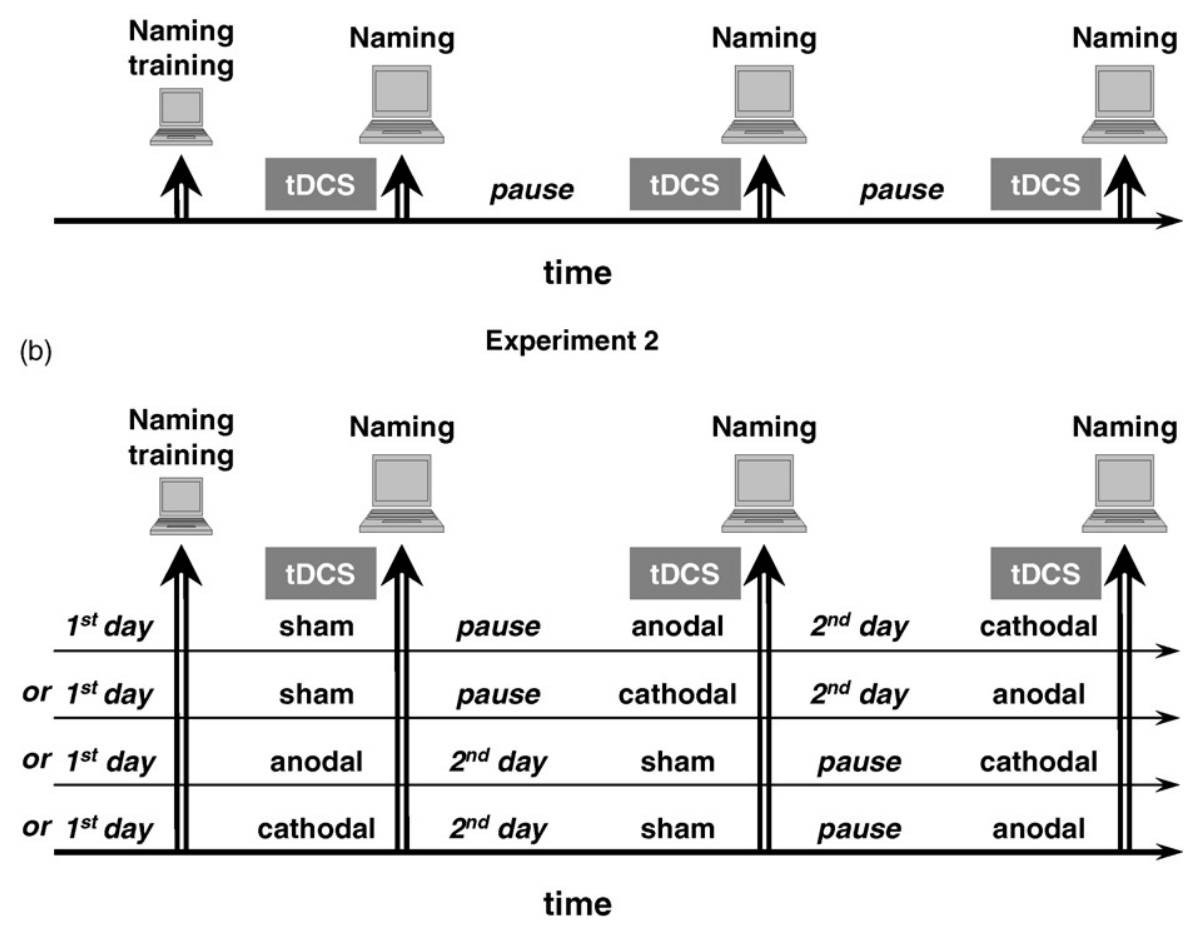

Fig. 2. (a) Procedure for the experiment 1. (b) Procedure for the experiment 2.

a pair of saline-soaked sponge electrodes $(7 \mathrm{~cm} \times 5 \mathrm{~cm})$. A constant current of $2 \mathrm{~mA}$ was applied for 8 (experiment 1 ) or 10 (experiment 2) min, with a ramping period of $10 \mathrm{~s}$ both at the beginning and at the end of the stimulation. The current density $\left(0.057 \mathrm{~mA} / \mathrm{cm}^{2}\right)$ was maintained below the safety limits [36]. The electrodes were kept firm by elastic bands and an electroconductive gel was applied under the electrodes before the montage, to reduce contact impedance. The so-called active electrode was placed on the left DLPFC, moving $8 \mathrm{~cm}$ frontally and $6 \mathrm{~cm}$ laterally with respect to the scalp vertex, which had been identified as $\mathrm{Cz}$ in 10-20 nomenclature for EEG electrode positioning [6]. The reference electrode was fixed on the right shoulder. We preferred an extracephalic reference to avoid unwelcome interference effects from brain areas underlying the reference electrode [38].

The study was a single-blind experiment: the individual subjects do not know the type of stimulation they received while the experimenter knew it. We applied three different stimulations on the left DLPFC: anodal, cathodal and sham (i.e., placebo). In the sham stimulation, the current was turned off $30 \mathrm{~s}$ after the beginning of the stimulation (duration of fade in and fade out period $=10 \mathrm{~s}$ ) and was turned on for the last $30 \mathrm{~s}$ of the stimulation period. In this way, the subjects felt the itching sensations below the electrodes at the beginning and at the end of the stimulation, making this condition indistinguishable from the real stimulation [14].

Moreover, to detect differences in the perception of sensation, we asked all of the subjects taking part in the experiment 2 to compile a questionnaire about the sensations experienced during the different types of stimulations (anodal, cathodal and sham). The questionnaire (see Appendix A) was partially based on a previous questionnaire presented by Poreisz et al. [36]. We chose to use this questionnaire to evaluate whether unspecific stimulation effects related to different experimental conditions could account for differences in behavioural performance.

\section{Procedure}

In the two experiments, subjects were seated in front of a computer screen, in a quiet room in semi-darkness. In the experiment 1 , they performed the picture naming task immediately after anodal, cathodal and sham stimulation. The three sessions and, therefore, three experimental blocks were separated by a 1-h pause (i.e., washing-out) period. Their order of execution was accurately balanced. The procedure is shown in Fig. 2a.

In experiment 2 , the subjects performed the picture naming task directly after anodal, cathodal and sham stimulation, as in experiment 1 . The active stimulations (i.e., anodal, cathodal) were executed on two different days, thus minimising the probability of interference effects. In this case, a complete balance of the stimulation order was not possible. The presentation order was semi-balanced. The sham stimulation was always the first stimulation performed on the first or second day (see Fig. 2b).

In addition, to exclude the possibility that the tDCS effect could be ascribed to non-specific stimulation effects or to a general enhancement of arousal, four subjects performed the attentive task four times, i.e., at the beginning and at the end of each of the two sessions each day.

\section{Data analysis}

The subjects' performances were recorded with a microphone placed in front of the participant. Vocal responses were digitised with the GoldWave v. 5.15 (GoldWave, Newfoundland, Canada) software, with a sampling rate of $11,025 \mathrm{~Hz}$.

We measured accuracy, giving 1 point to each error (no response, semantic error, visual error) and then calculating the mean for each subject in each condition.

The latency of the verbal response (vocal reaction time - vRT) was measured manually on the screen, marking the start of the wave corresponding to the vocal response. We eliminated from the 
analysis all incorrectly performed trials. In addition, we removed all data falling above or below two standard deviations with respect to the mean for each subject in each condition.

In the attentive control task, we analysed the manual RT. In this task Wilcoxon test was used for the small numerousness of the sample. For all the other data (vRT, accuracy), the Kolmogorov-Smirnov test confirmed the normality of the distribution, therefore data were subsequently analysed using repeated measures analysis of variance (ANOVA).

The data sphericity was tested using the Mauchly test where appropriate. When the test results were statistically significant, the data were corrected using the Huynn-Feldt correction. Moreover for multiple comparisons the $p$-values were corrected using Bonferroni correction.

\section{Results}

\subsection{Experiment 1}

All of the subjects tolerated the stimulation well; no subjects reported adverse effects or asked to interrupt the experiment.

\subsubsection{Accuracy}

A repeated measures ANOVA tDCS (anodal, cathodal, sham) by type of stimulus (object, action) did not show any significant difference between conditions for accuracy [tDCS: $F_{(2,22)}=1.219 ; p>0.05$ - type of stimuli: $F_{(1,11)}=3.973 ; p>0.05$ - tDCS by type of stimuli: $\left.F_{(2,22)}=0.288 ; p>0.05\right]$.

\subsubsection{Response times}

A repeated measures ANOVA tDCS (anodal, cathodal, sham) by type of stimulus (object, action) did not show a significant difference between conditions (mean vRT \pm standard deviation (SD) for actions: sham $=907 \pm 104 \mathrm{~ms}$, anodal $=871 \pm 78 \mathrm{~ms}$, cathodal $=916 \pm 129 \mathrm{~ms}$; and objects: $\quad$ ham $=739 \pm 81 \mathrm{~ms}$, anodal $=731 \pm 99 \mathrm{~ms}$, cathodal $=761 \pm 84 \mathrm{~ms}$ ).

Even if cathodal and anodal tDCS induce an opposite pattern of behaviour, data were highly variable between subjects overall. Considering this large data variability, we normalised the data. For each subject, we calculated the difference between the vRT in each stimulation condition (anodal or cathodal) and the sham vRT $\left(\mathrm{vRT}_{\text {sham }}\right)$, divided by $\mathrm{vRT}_{\text {sham }}$. The repeated measures ANOVA tDCS (anodal, cathodal) by type of stimuli (objects, actions) revealed a main effect of the tDCS factor $\left[F_{(11,37)}=6.015 ; p=0.032\right]$. Subjects denominated the stimuli faster after anodal stimulation than after cathodal stimulation (see Fig. 3a).

\subsection{Experiment 2}

We inferred that all of the subjects tolerated the stimulation by interpreting the spontaneous report as well as the question-
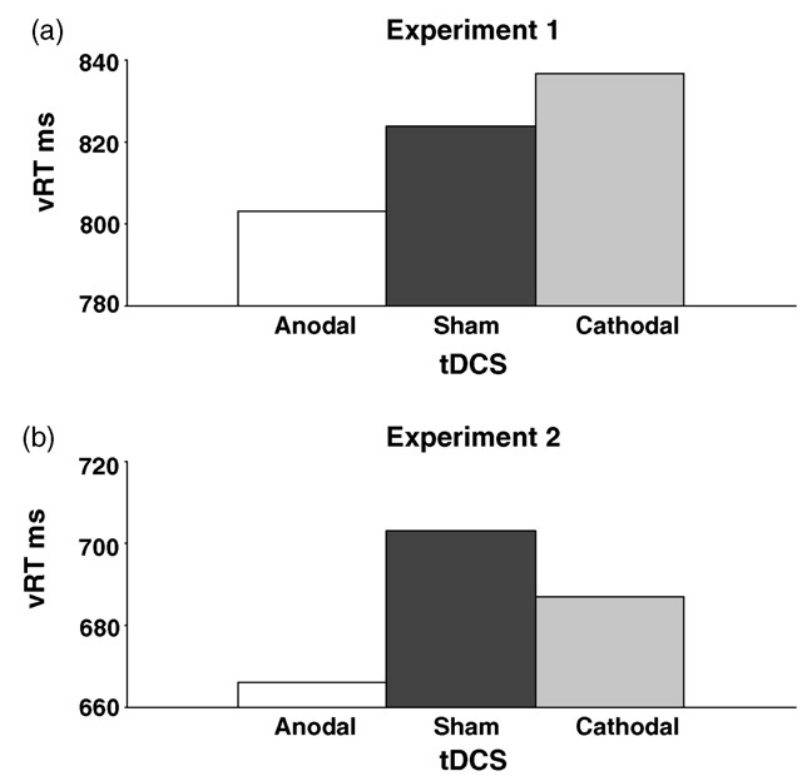

Fig. 3. Vocal reaction times (vRTs) of the two experiments: (a) experiment 1 and (b) experiment 2 . Along the abscissa, data are expressed in milliseconds.

naire completed by each subject at the end of the experiment (see Appendix A). The questionnaire results are reported in Table 1. Itch and irritation were the most commonly reported sensations (87\% and $77 \%$ of the subjects, respectively), with light to moderate intensity. None of the subjects were able to distinguish sham from real stimulation.

A multiple paired $t$-test did not show any significant difference in the subjects' perception of sensation between the real (anodal or cathodal) and the sham stimulation conditions.

\subsubsection{Accuracy}

A repeated measures ANOVA tDCS (anodal, cathodal, sham) by type of stimulus (object, action) shows only a significant main effect of the type of stimulus factor $\left[F_{(1,11)}=11.712 ; p<0.05\right]$ : participants made significantly fewer errors in object naming as compared to action naming.

\subsubsection{Response times}

A repeated measures ANOVA with tDCS (anodal, cathodal, sham) by stimulus factor type (objects, actions), shows a significant main effect of tDCS [Epsilon $=0.680, p=0.014-$ Huynh-Feldt $-F_{(1.359}$, $14.950)=4.194 ; p<0.05]$ and stimulus factor type $\left[F_{(1,11)}=253.916\right.$; $p<0.05]$. The interaction was not statistically significant $\left[F_{(2}\right.$, $22)=1.608 ; p>0.05]$. In regards to the main effect of the factor tDCS, multiple post-hoc comparisons revealed a statistically significant difference between sham (mean vRT $\pm S D=703 \pm 117 \mathrm{~ms}$ )

\section{Table 1}

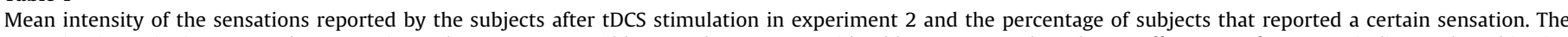

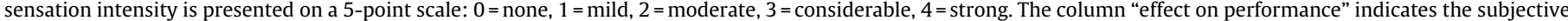
feeling of the participant relative to how much did the tDCS induced sensations affect his performance.

\begin{tabular}{|c|c|c|c|c|c|c|c|c|}
\hline $\mathrm{tDCS}$ & Irritation & Pain & Burning & Heat & Itch & Iron taste & Fatigue & Effect on performance \\
\hline \multicolumn{9}{|l|}{ Sham } \\
\hline Intensity & 0.9 & 0.0 & 0.4 & 0.3 & 1.3 & 0.4 & 0.0 & 0.2 \\
\hline Subjects (\%) & 77 & 0 & 31 & 15 & 85 & 15 & 0 & 15 \\
\hline \multicolumn{9}{|l|}{ Anodal } \\
\hline Intensity & 1.4 & 0.2 & 0.7 & 0.4 & 1.8 & 0.8 & 0.0 & 0.3 \\
\hline Subjects (\%) & 77 & 15 & 38 & 38 & 85 & 38 & 0 & 23 \\
\hline \multicolumn{9}{|l|}{ Cathodal } \\
\hline Intensity & 0.9 & 0.0 & 0.6 & 0.3 & 1.3 & 0.8 & 0.0 & 0.3 \\
\hline Subjects (\%) & 77 & 0 & 38 & 23 & 92 & 38 & 0 & 15 \\
\hline
\end{tabular}


and anodal (mean vRT \pm SD $=666 \pm 92 \mathrm{~ms}$ ) stimulation (see Fig. 3b). Participants were faster after anodal stimulation. Cathodal stimulation (mean $v R T=S D=687 \pm 90 \mathrm{~ms}$ ) did not differ significantly from sham stimulation.

The main effect of the stimulus type shows that subjects were faster at object naming than at action naming (mean $\mathrm{vRT} \pm \mathrm{SD}$ for actions: sham $=789 \pm 100 \mathrm{~ms}$, anodal $=741 \pm 58 \mathrm{~ms}$, cathodal $=757 \pm 60 \mathrm{~ms}$; $\quad$ and objects: $\quad$ sham $=617 \pm 51 \mathrm{~ms}$, anodal $=590 \pm 47 \mathrm{~ms}$, cathodal $=616 \pm 51 \mathrm{~ms}$ ). The lack of a statistically significant interaction indicates that the facilitation after anodal stimulation was present for both action and object naming.

As in experiment 1, data were normalised and a repeated measures ANOVA with tDCS (anodal, cathodal) by type of stimulus (object, action) underscored a main effect of the tDCS factor $\left[F_{(11}\right.$, $37)=8.130 ; p=0.016]$. As revealed by the previous analyses, subjects were faster at naming the stimuli in the anodal as compared to the cathodal condition.

Regarding the attentive control task, we calculate the difference in the RT before and after the anodal (pre-post anodal) and the cathodal (pre-post cathodal) stimulation. The text of Wilcoxon did not show a significant difference between the pre-post anodal and the pre-post cathodal condition $(Z=-0.535 ; p>0.05)$. We conclude that the performance in the attentive control task was not influenced by the different types of stimulation (mean $\mathrm{RT} \pm \mathrm{SD}$ in each condition: pre-anodal $=293 \pm 17 \mathrm{~ms}$, post-anodal $=$ $290 \pm 20 \mathrm{~ms}, \quad$ pre-cathodal $=293 \pm 13 \mathrm{~ms}, \quad$ post - cathodal $=$ $291 \pm 13 \mathrm{~ms})$.

\section{Discussion}

In this study, we show that anodal stimulation of the left DLPFC exerts a facilitation effect on picture naming in healthy subjects. The absence of a significant differential stimulation effect on the attentive task or on the perception of sensations questionnaire ruled out the possibility of facilitation due to non-specific effects, such as enhancement of arousal or attention. Moreover, the observation of a facilitatory effect in both experiments indicates robustness of the result.

Our experiments do not highlight any effect of cathodal stimulation, since reaction times in the cathodal conditions are not different from those in the sham conditions. In animal $[4,39]$ and human motor cortex $[29,30]$ studies, general cathodal effects are described, as opposed to those induced by anodal stimulation (inhibition vs. facilitation). Nevertheless, there are several studies in the cognitive domain that report the absence of inhibitory effects after cathodal stimulation $[12,13,19,43]$, which is consistent with our results.

On the other hand, the experiments presented herein highlight the facilitatory effect of anodal stimulation, namely faster vocal reaction time. The facilitation effect that we observed is similar to that described by Sparing et al. [43] with anodal stimulation of Wernicke's area. Nevertheless, many differences between our study and theirs make comparison of the results difficult. In contrast to our study, their study focused strictly on object naming and the stimuli were over-trained to obtain stable reaction times with regard to naming. Furthermore, they adopted a cephalic collocation of the reference electrode. Analogous difficulties are present when comparing these findings with the results of Monti et al. [25]. The cathodal facilitation that they highlight is surely difficult to explain, although the current distribution in brains with diffuse atrophy is certainly different from that in a healthy brain [46].

The facilitation observed in our study is consistent with previous data showing that high frequency rTMS on the left DLPFC shortens the time necessary for naming in young healthy subjects
[6] and in patients with Alzheimer's disease [7,8]. A notable difference to the Cappa et al. [6] rTMS study, which was performed on young normal subjects, is the reduced specificity of the obtained effect in our study. In the present tDCS experiment, the facilitation was for action as well as for object naming, while the facilitation was present only for action naming during an on-line protocol in the Cappa et al. [6] study. A possible explanation for this distinction is the amplitude of the area of the electrodes used for tDCS (i.e., $35 \mathrm{~cm}^{2}$ ) as compared to the smaller TMS stimulation area of the figure-eight coil (i.e., $\sim 2 \mathrm{~cm}^{2}$ around the intersection point of the coil) [45]. Therefore, it seems that our stimulation had a more general influence on the network involved in the naming task. In addition, the differential effects on behavioural response might be dependent upon the timing of stimulation (i.e., on-line vs. off-line). The effects induced by on-line stimulation are generally shortlived, probably on the order of a few hundred milliseconds to a few seconds, while use of the off-line approach allows for transient modulation of long-term neural excitability. This difference in duration may be related to a differential modulation of the neural network that controls language.

Another difference related to studies with rTMS involves the mechanism underlying behavioural performance. While rTMS is a neurostimulation technique that is able to induce action potentials in the stimulated area, tDCS is a neuromodulation technique $[27,46]$. Therefore, short-term effects of tDCS are due respectively to a decrease (anodal) or an increase (cathodal) of the resting neuronal threshold [21]. Nevertheless, in our study, behavioural facilitatory effects after the end of the stimulation period (i.e., offline), are very likely induced by long-term modulatory effects on the activation state of the target area. This could appear in disagreement with the rules of the homeostatic plasticity, which sustain that low background activity would enhance facilitatory plasticity, whereas high background activity would inhibit it. Nevertheless this kind of assumption has been demonstrated in tDCS studies only on the human motor cortex and with conditioning protocols employing rTMS [20,42]. Nitsche et al. [32], with another conditioning paradigm, obtain results coherent with the homeostatic plasticity only when this paradigm was applied simultaneously with the tDCS stimulation, and not when it was applied, like in our experiment, after the stimulation. These data seem confirmed also by a number of cognitive studies, that highlight facilitation when a cognitive task is performed after the anodal stimulation [e.g., 5,34,43].

We conclude that polarisation by anodal tDCS of the underlying brain tissue and of the remote connected areas has had a more general influence on the network involved in the naming task. More specifically, since it has been demonstrated that language operations mediated by prefrontal cortex are involved in word retrieval $[1,18]$, and that word retrieval includes searching and monitoring as well as selecting the appropriate word from among competing alternatives $[1,18]$, we suggest that the cerebral network dedicated to lexical retrieval processing is facilitated by anodal tDCS to left DLPFC. Although the detailed mechanisms responsible for facilitation are not completely understood, they seem to involve long-term potentiation $[21,28]$. Since it has been demonstrated that shortterm tDCS effects are related to membrane depolarisation (anodal stimulation) while long-term tDCS effects involve the participation of glutamatergic NMDA receptors and that synaptic plasticity is dependent on NMDA receptors, we can hypothesize that the result obtained might depend from these mechanisms.

This finding suggests that behavioural improvements may be induced in patients with cognitive deficits through stimulation/facilitation of the adequate network to solve a given task. Further, in an ideal neurorehabilitation approach, these improvements could become long-lasting effects through the strengthening effects of neural learning by cognitive training [24]. 
In conclusion, we found that anodal stimulation of the left DLPFC modulates the behavioural performance of healthy subjects in a picture naming task, demonstrating that left DLPFC is part of cerebral network dedicated to lexical retrieval/selection processing in naming. Moreover this study has revealed promising results in terms of the potential effectiveness of inducing a tDCS facilitatory effect in a linguistic elaboration process that is surely able to open new and promising scenarios in the field of language rehabilitation.

\section{Acknowledgement}

We thank Umberto Boldi for some help with data collection

\section{Appendix A.}

Survey of sensations related to transcranial direct current stimulation English and Italian versions.

Subject code:

Date:

Experiment:

Have you experienced any sensation during the direct current stimulation? Please answer to the following questions regarding the different sensations, indicating the degree of intensity of your perception according to the following scale:

- $\underline{\text { None }}=\mathrm{I}$ have not felt the described sensation

- $\underline{\text { Mild }}=\mathbf{I}$ have mildly felt the described sensation

- $\underline{\text { Moderate }}=\mathrm{I}$ have felt the described sensation

- $\underline{\text { Considerable }}=\mathrm{I}$ have felt the described sensation to a considerable degree

- $\underline{\text { Strong }}=$ I have strongly felt the described sensation

\section{In the first stimulation block}

\begin{tabular}{|c|c|c|c|c|}
\hline Itchiness: & $\square$ None & $\square$ Mild & $\square$ Moderate & $\square$ Considerable $\square$ Strong \\
\hline Pain: & $\square$ None & $\square$ Mild & $\square$ Moderate & $\square$ Considerable $\square$ Strong \\
\hline Burning: & $\square$ None & $\square$ Mild & $\square$ Moderate & $\square$ Considerable $\square$ Strong \\
\hline Warmth/Heat: & $\square$ None & $\square$ Mild & $\square$ Moderate & $\square$ Considerable $\square$ Strong \\
\hline Pinching: & $\square$ None & $\square$ Mild & $\square$ Moderate & $\square$ Considerable $\square$ Strong \\
\hline Iron taste: & $\square$ None & $\square$ Mild & $\square$ Moderate & $\square$ Considerable $\square$ Strong \\
\hline Fatigue: & $\square$ None & $\square$ Mild & $\square$ Moderate & $\square$ Considerable $\square$ Strong \\
\hline Other & $\square$ None & $\square$ Mild & $\square$ Moderate & $\square$ Considerable $\square$ Strong \\
\hline
\end{tabular}

When did the sensations begin?

$\square$ At the beginning of the block $\square$ About the middle of the block $\square$ Towards the end of the block

How long did they last?

$\square$ They stopped soon $\quad \square$ They stopped in the middle of the block $\square$ They stopped at the end of the block How much did these sensations affect your performance?

$$
\square \text { Not at all } \square \text { A little } \square \text { Considerably } \quad \square \text { Much } \quad \square \text { Very much }
$$

\section{In the second stimulation block}

If you want to provide more details, please briefly describe the experimented sensations in relation to:

- Itchiness:

- Pain:

- Burning:

- Warmth/Heat:

- Pinching:

- Iron taste:

- Fatigue:

- Other: 
Codice Soggetto:

Data:

I

Esperimento/Sperimentatore:

Che sensazioni ha percepito durante la stimolazione elettrica a corrente continua? Risponda alle seguenti domande indicando il grado di intensità con il quale ha percepito ognuna delle sensazioni elencate, utilizzando una scala come la seguente:

- $\underline{\text { Nessuno }}=$ non ho avvertito alcuna sensazione del tipo descritto

- $\underline{\text { Lieve }}=$ la sensazione descritta è stata appena avvertita

- $\underline{\text { Moderato }}=$ la sensazione descritta è stata avvertita

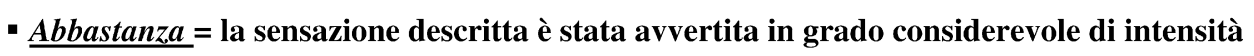

- $\underline{\text { Molto }}=$ la sensazione descritta è stata avvertita come forte

\section{Nel primo blocco di stimolazione}

\begin{tabular}{|c|c|c|c|c|c|}
\hline Prurito: & $\square$ Nessuno & $\square$ Lieve & $\square$ Moderato & $\square$ Abbastanza & $\square$ Molto \\
\hline Dolore: & $\square$ Nessuno & $\square$ Lieve & $\square$ Moderato & $\square$ Abbastanza & $\square$ Molto \\
\hline Bruciore: & $\square$ Nessuno & $\square$ Lieve & $\square$ Moderato & $\square$ Abbastanza & $\square$ Molto \\
\hline Calore: & $\square$ Nessuno & $\square$ Lieve & $\square$ Moderato & $\square$ Abbastanza & $\square$ Molto \\
\hline Pizzicore: & $\square$ Nessuno & $\square$ Lieve & $\square$ Moderato & $\square$ Abbastanza & $\square$ Molto \\
\hline Sapore Ferroso: & $\square$ Nessuno & $\square$ Lieve & $\square$ Moderato & $\square$ Abbastanza & $\square$ Molto \\
\hline Affaticamento: & $\square$ Nessuno & $\square$ Lieve & $\square$ Moderato & $\square$ Abbastanza & $\square$ Molto \\
\hline Altro_ & $\square$ Nessuno & $\square$ Lieve & $\square$ Moderato & $\square$ Abbastanza & $\square \mathrm{Mol}$ \\
\hline
\end{tabular}

Quando sono insorte le sensazioni?

$$
\square \text { All'inizio } \square \text { Verso la metà del blocco di stimolazione } \square \text { Verso la fine }
$$

Per quanto tempo sono durate?

$\square$ sono subito svanite $\square$ sono svanite verso la metà del blocco $\square$ sono durate fino alla fine del blocco

Quanto le sensazioni provate hanno influenzato la qualità della sua prestazione in questo blocco?

$$
\square \text { Per Nulla } \square \text { Poco } \square \text { Abbastanza } \square \text { Molto } \square \text { Moltissimo }
$$

\section{$\underline{\text { Nel secondo blocco di stimolazione }}$}

$\cdots$

Se lo ritiene opportuno, descriva brevemente le sensazioni da lei provate riguardo a:

- Prurito:

- Dolore:

- Bruciore:

- Calore:

- Pizzicore:

- Sapore ferroso:

- Affaticamento:

- Altro:

\section{References}

[1] Alexander MP, Benson DF, Stuss DT. Frontal lobes and language. Brain Lang 1989;37:656-91.

[2] Antal A, Nitsche MA, Kruse W, Kincses TZ, Hoffmann KP, Paulus W. Direct current stimulation over V5 enhances visuomotor coordination by improving motion perception in humans. J Cogn Neurosci 2004;16: 521-7.

[3] Bates E, Andonova E, D’Amico S, Jacobsen T, Kohnert K, Lu CC, et al. Introducing the CRL International Picture Naming Project (CRL-IPNP). Center for Research in Language Newsletter. La Jolla: University of California San Diego; 2000 (12).

[4] Bindman LJ, Lippold OC, Redfearn JW. The action of brief polarizing currents on the cerebral cortex of the rat (1) during current flow and (2) in the production of long-lasting after-effects. J Physiol 1964;172:369-82.
[5] Boggio PS, Khoury LP, Martins DC, Martins OE, de Macedo EC, Fregni F. Temporal cortex direct current stimulation enhances performance on a visual recognition memory task in Alzheimer disease. J Neurol Neurosurg Psychiatry 2009;80:444-7.

[6] Cappa SF, Sandrini M, Rossini PM, Sosta K, Miniussi C. The role of the left frontal lobe in action naming: rTMS evidence. Neurology 2002;59: 720-3.

[7] Cotelli M, Manenti R, Cappa SF, Geroldi C, Zanetti O, Rossini PM, et al. Effect of transcranial magnetic stimulation on action naming in patients with Alzheimer disease. Arch Neurol 2006;63:1602-4.

[8] Cotelli M, Manenti R, Cappa SF, Zanetti O, Miniussi C. Transcranial magnetic stimulation improves naming in Alzheimer disease patients at different stages of cognitive decline. Eur J Neurol 2008;15:1286-92.

[9] Creutzfeldt OD, Fromm GH, Kapp H. Influence of transcortical dc currents on cortical neuronal activity. Exp Neurol 1962;5:436-52. 
[10] DeLeon J, Gottesman RF, Kleinman JT, Newhart M, Davis C, Heidler-Gary J, et al. Neural regions essential for distinct cognitive processes underlying picture naming. Brain 2007;130:1408-22.

[11] Finocchiaro C, Maimone M, Brighina F, Piccoli T, Giglia G, Fierro B. A case study of primary progressive aphasia: improvement on verbs after rTMS treatment. Neurocase 2006;12:317-21.

[12] Floel A, Rosser N, Michka O, Knecht S, Breitenstein C. Noninvasive brain stimulation improves language learning. J Cogn Neurosci 2008;20:1415-22.

[13] Fregni F, Boggio PS, Nitsche M, Bermpohl F, Antal A, Feredoes E, et al. Anodal transcranial direct current stimulation of prefrontal cortex enhances working memory. Exp Brain Res 2005;166:23-30.

[14] Gandiga PC, Hummel FC, Cohen LG. Transcranial DC stimulation (tDCS): a tool for double-blind sham-controlled clinical studies in brain stimulation. Clin Neurophysiol 2006;117:845-50.

[15] Gartside IB. Mechanisms of sustained increases of firing rate of neurones in the rat cerebral cortex after polarization: role of protein synthesis. Nature 1968;220:383-4.

[16] Gartside IB. Mechanisms of sustained increases of firing rate of neurons in the rat cerebral cortex after polarization: reverberating circuits or modification of synaptic conductance? Nature 1968;220:382-3.

[17] Iyer MB, Mattu U, Grafman J, Lomarev M, Sato S, Wassermann EM. Safety and cognitive effect of frontal DC brain polarization in healthy individuals. Neurology 2005;64:872-5.

[18] Kerns JG, Cohen JD, Stenger VA, Carter CS. Prefrontal cortex guides contextappropriate responding during language production. Neuron 2004:43:283-91.

[19] Kincses TZ, Antal A, Nitsche MA, Bartfai O, Paulus W. Facilitation of probabilistic classification learning by transcranial direct current stimulation of the prefrontal cortex in the human. Neuropsychologia 2004;42:113-7.

[20] Lang N, Siebner HR, Ernst D, Nitsche MA, Paulus W, Lemon RN, et al. Preconditioning with transcranial direct current stimulation sensitizes the motor cortex to rapid-rate transcranial magnetic stimulation and controls the direction of after-effects. Biol Psychiatry 2004;56:634-9.

[21] Liebetanz D, Nitsche MA, Tergau F, Paulus W. Pharmacological approach to the mechanisms of transcranial DC-stimulation-induced after-effects of human motor cortex excitability. Brain 2002;125:2238-47.

[22] Liljestrom M, Tarkiainen A, Parviainen T, Kujala J, Numminen J, Hiltunen J, et al. Perceiving and naming actions and objects. Neuroimage 2008;41:1132-41.

[23] Luzzatti C, Raggi R, Zonca G, Pistarini C, Contardi A, Pinna GD. Verb-noun double dissociation in aphasic lexical impairments: the role of word frequency and imageability. Brain Lang 2002;81:432-44.

[24] Miniussi C, Cappa SF, Cohen LG, Floel A, Fregni F, Nitsche M, et al. Efficacy of repetitive transcranial magnetic stimulation/transcranial direct current stimulation in cognitive neurorehabilitation. Brain Stimulat 2008;1:326-36.

[25] Monti A, Cogiamanian F, Marceglia S, Ferrucci R, Mameli F, Mrakic-Sposta S, et al. Improved naming after transcranial direct current stimulation in aphasia. J Neurol Neurosurg Psychiatry 2008;79:451-3.

[26] Morris RG, Anderson E, Lynch GS, Baudry M. Selective impairment of learning and blockade of long-term potentiation by an $N$-methyl-D-aspartate receptor antagonist, AP5. Nature 1986;319:774-6.

[27] Nitsche M, Cohen LG, Wassermann EM, Priori A, Lang N, Antal A, et al. Transcranial direct current stimulation: state of the Art 2008. Brain Stimulat 2008;1:206-23.

[28] Nitsche MA, Fricke K, Henschke U, Schlitterlau A, Liebetanz D, Lang N, et al. Pharmacological modulation of cortical excitability shifts induced by transcranial direct current stimulation in humans. J Physiol 2003;553: 293-301.

[29] Nitsche MA, Nitsche MS, Klein CC, Tergau F, Rothwell JC, Paulus W. Level of action of cathodal DC polarisation induced inhibition of the human motor cortex. Clin Neurophysiol 2003;114:600-4.

[30] Nitsche MA, Paulus W. Excitability changes induced in the human motor cortex by weak transcranial direct current stimulation. J Physiol 2000;527(Pt 3):633-9.

[31] Nitsche MA, Paulus W. Sustained excitability elevations induced by transcranial DC motor cortex stimulation in humans. Neurology 2001;57:1899-901.

[32] Nitsche MA, Roth A, Kuo MF, Fischer AK, Liebetanz D, Lang N, et al. Timingdependent modulation of associative plasticity by general network excitability in the human motor cortex. J Neurosci 2007;27:3807-12.

[33] Nitsche MA, Schauenburg A, Lang N, Liebetanz D, Exner C, Paulus W, et al. Facilitation of implicit motor learning by weak transcranial direct current stimulation of the primary motor cortex in the human. J Cogn Neurosci 2003;15:619-26.

[34] Ohn SH, Park CI, Yoo WK, Ko MH, Choi KP, Kim GM, et al. Time-dependent effect of transcranial direct current stimulation on the enhancement of working memory. Neuroreport 2008;19:43-7.

[35] Perani D, Cappa SF, Schnur T, Tettamanti M, Collina S, Rosa MM, et al. The neural correlates of verb and noun processing. A PET study. Brain 1999;122:2337-44.

[36] Poreisz C, Boros K, Antal A, Paulus W. Safety aspects of transcranial direct current stimulation concerning healthy subjects and patients. Brain Res Bull 2007;72:208-14.

[37] Priori A. Brain polarization in humans: a reappraisal of an old tool for prolonged non-invasive modulation of brain excitability. Clin Neurophysiol 2003;114:589-95.

[38] Priori A, Mameli F, Cogiamanian F, Marceglia S, Tiriticco M, Mrakic-Sposta S, et al. Lie-specific involvement of dorsolateral prefrontal cortex in deception. Cereb Cortex 2008;18:451-5.

[39] Purpura DP, McMurtry JG. Intracellular activities and evoked potential changes during polarization of motor cortex. J Neurophysiol 1965;28:166-85.

[40] Serruya MD, Kahana MJ. Techniques and devices to restore cognition. Behav Brain Res 2008;192:149-65.

[41] Shapiro KA, Moo LR, Caramazza A. Cortical signatures of noun and verb production. Proc Natl Acad Sci U S A 2006;103:1644-9.

[42] Siebner HR, Lang N, Rizzo V, Nitsche MA, Paulus W, Lemon RN, et al. Preconditioning of low-frequency repetitive transcranial magnetic stimulation with transcranial direct current stimulation: evidence for homeostatic plasticity in the human motor cortex. J Neurosci 2004;24:3379-85.

[43] Sparing R, Dafotakis M, Meister IG, Thirugnanasambandam N, Fink GR. Enhancing language performance with non-invasive brain stimulation-a transcranial direct current stimulation study in healthy humans. Neuropsychologia 2008;46:261-8.

[44] Vines BW, Schnider NM, Schlaug G. Testing for causality with transcrania direct current stimulation: pitch memory and the left supramarginal gyrus. Neuroreport 2006;17:1047-50.

[45] Wagner T, Eden U, Fregni F, Valero-Cabre A, Ramos-Estebanez C, Pronio-Stelluto $\mathrm{V}$, et al. Transcranial magnetic stimulation and brain atrophy: a computerbased human brain model study. Exp Brain Res 2008;186:539-50.

[46] Wagner T, Fregni F, Fecteau S, Grodzinsky A, Zahn M, Pascual-Leone A. Transcranial direct current stimulation: a computer-based human model study. Neuroimage 2007;35:1113-24. 